\title{
Origen anómalo de la coronaria izquierda corregido con maniobra modificada de Lecompte
}

\author{
Abnormal origin of the left coronary artery corrected with modified Lecompte maneuver \\ Adrián Bolívar-Mejía ${ }^{*}$, Pedro Abad², Carlos Martínez³, Juan C. Rendón ${ }^{4}$, Jorge Zapata ${ }^{4}$ y \\ Clara Saldarriaga-Giraldo ${ }^{5}$ \\ ${ }^{1}$ Servicio de Cardiología, Clínica Cardio VID. Posgrado de Cardiología, Universidad Pontifica Bolivariana; ${ }^{2}$ Consultor de cardioimágenes y radiólogo \\ de ayudas diagnósticas, SURA; ${ }^{3}$ Servicio de Cardiología, Clínica Cardio VID; ${ }^{4}$ Servicio de Cirugía Cardiovascular, Clínica Cardio VID, Coordinación \\ del Posgrado de Cardiología, Universidad Pontificia Bolivariana. ${ }^{5}$ Servicio de Cardiología y Falla Cardiaca, Clínica Cardio VID. Medellín, Colombia
}

La irrigación cardiaca normal viene dada por el origen de las arterias coronarias derecha e izquierda a nivel de los senos coronarianos derecho e izquierdo; sin embargo, pueden presentarse modificaciones de la anatomía descrita, algunas de las cuales corresponden a variantes inocuas, mientras que otras pueden asociarse con alto riesgo de morbimortalidad ${ }^{1,2}$.

\section{Caso clínico}

Mujer de 54 años con antecedente de hipercolesterolemia controlada con rosuvastatina (10 mg/día). Consultó por 4 meses de dolor torácico de carácter punzante que se presentaba indistintamente en reposo o ejercicio. Ocasionalmente se asociaba a disnea, irradiándose a la región interescapular. La exploración física y el electrocardiograma fueron normales. Se indicó ecocardiograma de estrés con ejercicio, el cual fue submáximo (75\%), no concluyente para isquemia. La función ventricular izquierda era normal.

Se indicó reestratificación del riesgo con puntuación de calcio coronario, que informó una puntuación de Agatston de 0 , describiéndose adicionalmente un posible origen anómalo de la coronaria derecha. Se realizó angiotomografía coronaria, en la cual se documentó la coronaria derecha de origen y trayecto normales, y origen anómalo del tronco principal izquierdo, $5 \mathrm{~mm}$ cefálico a la unión sinotubular sobre el seno coronariano derecho, con trayecto entre la aorta y la arteria pulmonar (Fig. 1). Se realizó una coronariografía que descartó enfermedad aterosclerótica.

La paciente fue llevada a descompresión de la coronaria izquierda con maniobra modificada de Lecompte (Fig. 2) y cursó con una adecuada evolución posoperatoria. En el seguimiento realizado tras 5 meses de la intervención quirúrgica se encuentra asintomática, con clase funcional I/IV de la New York Heart Association.

\section{Discusión}

El origen anómalo de las arterias coronarias corresponde a alteraciones congénitas presentes en menos del $1 \%$ de la población, las cuales pueden cursar de forma asintomática o generar episodios de angina, disnea, síncope o muerte súbita cardiaca ${ }^{1,2}$.

La anomalía más frecuente es un origen de la descendente anterior y de la circunfleja desde ostium diferentes, hallazgo que no suele asociarse con repercusiones hemodinámicas ${ }^{1,2}$. Otras alteraciones menos frecuentes son un origen contralateral del ostium de las coronarias o la presencia de una arteria coronaria 


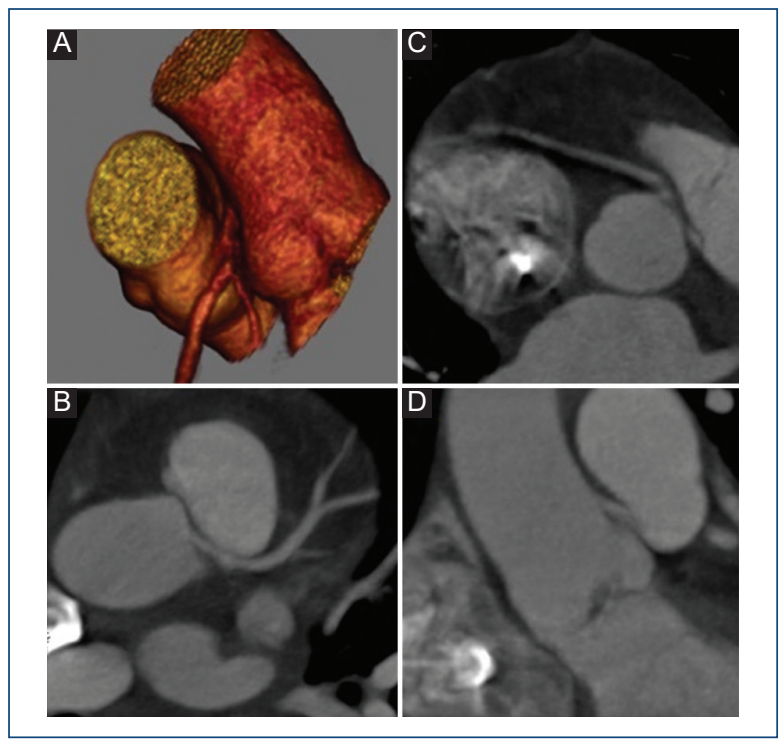

Figura 1. Angiotomografía coronaria. A: reconstrucción tridimensional que muestra el curso interarterial del tronco de la coronaria izquierda sin evidencia de recorrido intramural. B: visión transversa que evidencia el origen y el curso normal de la coronaria derecha. C y D: visión transversa (C) y coronal (D) del origen anómalo y el trayecto interarterial de la coronaria izquierda.

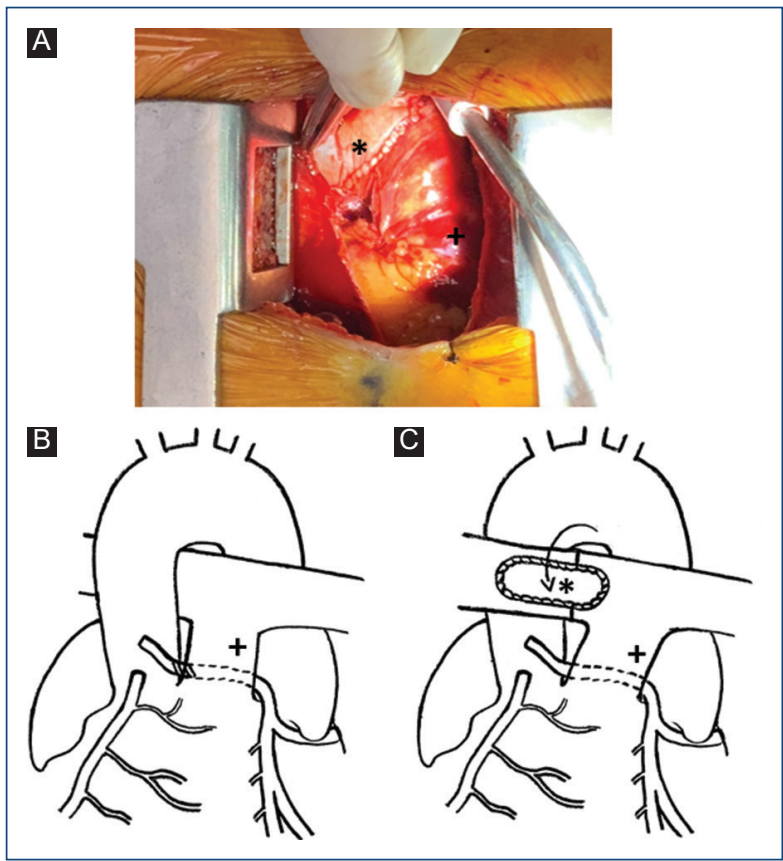

Figura 2. A: fotografía del resultado intraoperatorio de nuestra paciente tras la realización de la maniobra modificada de Lecompte. B y C: ilustración de la translocación del tronco de la pulmonar mediante la maniobra modificada de Lecompte. +: tronco de la arteria pulmonar. *: parche pericárdico sobre la rama derecha de la arteria pulmonar. única $^{1,3}$. Una vez que el vaso emerge del seno coronariano contralateral puede tomar diferentes trayectos: anterior al tronco de la pulmonar, retroaórtico, intramiocárdico subpulmonar a través del tabique, retrocardiaco o interarterial ${ }^{1}$. El riesgo de muerte súbita se encuentra relacionado con las características anatómicas de la anomalía cororonaria. Así, un trayecto entre la aorta y el tronco de la pulmonar, como en el presente caso, suele condicionar un mayor riesgo de muerte súbita debido a la compresión entre estos dos vasos. Otras anomalías asociadas a muerte súbita son el origen anómalo de la coronaria izquierda desde la arteria pulmonar, la atresia del tronco principal de la coronaria izquierda y la presencia de fístulas coronarias ${ }^{1,2}$.

El proceso diagnóstico debe tener como base las manifestaciones clínicas del paciente, considerando que los síntomas pueden ser atípicos, y al presentarse en pacientes usualmente jóvenes, sin factores de riesgo cardiovascular, puede llevar a subestimar la probabilidad de cardiopatía isquémica ${ }^{4}$.

Las herramientas diagnósticas incluyen la angiotomografía coronaria, la resonancia cardiaca y la arteriografía coronaria, la cual puede acompañarse de ultrasonido intravascular y tomografía de coherencia óptica; herramientas que permiten evaluar con mejor detalle el lumen del vaso y que aportan información relevante para definir la necesidad de intervención quirúrgica y la técnica quirúrgica a emplear ${ }^{3-5}$.

El manejo quirúrgico está indicado siempre que se documenten síntomas o hallazgos en estudios complementarios compatibles con isquemia asociada a la anomalía coronaria (recomendación IB), siendo razonable (recomendación Ila) en pacientes con origen de la coronaria izquierda en el seno coronariano derecho aun en ausencia de síntomas, escenario en el que se deben tener en consideración los aspectos anatómicos de alto riesgo previamente descritos ${ }^{5}$.

Se han descrito diferentes estrategias quirúrgicas, las cuales dependen de las características anatómicas del origen de la anomalía coronaria y del trayecto del vaso tras su emergencia del ostium ${ }^{6}$. La maniobra modificada de Lecompte es un procedimiento para el manejo del origen anómalo de las coronarias cuyo trayecto no implica un curso intramural ${ }^{6}$. Consiste en una translocación anterior del tronco de la pulmonar que permita ampliar el espacio interarterial entre dicho vaso y la aorta, para con esto evitar la compresión de la coronaria con curso interarterial y omitir la necesidad de reimplantar el vaso comprometido 6 . Por ello, la anatomía coronaria de nuestra paciente la convertía en una adecuada candidata a esta intervención, la cual fue realizada sin 
complicaciones, logrando una adecuada evolución posoperatoria y el egreso hospitalario 3 días después de la cirugía, encontrándose la paciente asintomática cardiovascular tras 5 meses de seguimiento posoperatorio.

\section{Conclusión}

El presente caso refleja la importancia del enfoque individualizado del dolor torácico, el cual no puede estar sesgado por la presencia o la ausencia de factores de riesgo cardiovascular clásicos ni enmarcarse bajo los puntajes de riesgo tradicionalmente empleados, dado que la cardiopatía isquémica no se limita a la enfermedad aterosclerótica y puede ser explicada en algunas ocasiones por la presencia de anomalías congénitas de la circulación coronaria.

\section{Conflictos de intereses}

Ninguno.

\section{Financiación}

La presente investigación no ha recibido ninguna beca específica de agencias de los sectores público, comercial o sin ánimo de lucro.

\section{Responsabilidades éticas}

Protección de personas y animales. Los autores declaran que para esta investigación no se han realizado experimentos en seres humanos ni en animales.

Confidencialidad de los datos. Los autores declaran que han seguido los protocolos de su centro de trabajo sobre la publicación de datos de pacientes.

Derecho a la privacidad y consentimiento informado. Los autores declaran que en este artículo no aparecen datos de pacientes.

\section{Bibliografía}

1. Harky A, Noshirwani A, Karadakhy O, Ang J. Comprehensive literature review of anomalies of the coronary arteries. J Card Surg. 2019;34: 1328-43.

2. Kastellanos S, Aznaouridis K, Vlachopoulos C, Tsiamis E, Oikonomou E, Tousoulis D. Overview of coronary artery variants, aberrations and anomalies. World J Cardiol. 2018;10:127-40.

3. Martín M, Avanzas $P$, Corros C, Fernández-Cimadevilla QC, León D, Barreiro M, et al. Arteria coronaria única con origen en seno de Valsalva derecho. Utilidad de la angiotomografía coronaria con tomografía multicorte. Cardiol Mex. 2011:81:327-9.

4. Gayás Ordás J, Linares Vicente JA, Angulo Hervias E, Revilla Martí P, Ruiz Arroyo JR. ¿Dónde está el tronco coronario izquierdo? Cardiol Mex. 2018;88:514-7.

5. Stout KK, Daniels CJ, Aboulhosn JA, Bozkurt B, Broberg CS, Colman JM, et al. 2018 AHA/ACC Guideline for the Management of Adults With Congenital Heart Disease: A Report of the American College of Cardiology/American Heart Association Task Force on Clinical Practice Guidelines. J Am Coll Cardiol. 2019;73:e81-e192.

6. Mainwaring RD, Reddy VM, Reinhartz O, Petrossian E, Punn R, Hanley FL. Surgical repair of anomalous aortic origin of a coronary artery. Eur J Cardiothorac Surg. 2014;46:20-6. 